\title{
Thyroid dysfunction after radiotherapy and chemotherapy of brain tumours
}

\author{
E A LIVESEY AND C G D BROOK \\ Endocrine Unit, Middlesex Hospital, London
}

SUMMARY We investigated thyroid function in 119 survivors of treatment for brain tumours not involving the hypothalamo-pituitary region. Cranial irradiation did not effect thyroid function but 11 of 47 children $(23 \%)$ who had spinal irradiation had raised concentrations of thyroid stimulating hormone. Chemotherapy further increased the incidence of thyroid dysfunction: two of four patients who had cranial irradiation and chemotherapy and 20 of 29 patients (69\%) who had spinal irradiation and chemotherapy had increased thyroid stimulating hormone concentrations. Only six patients with raised thyroid stimulating hormone concentrations had low serum thyroxine concentrations. Four children had secondary hypothyroidism.

Thyroid function should be monitored in children who have received chemotherapy or radiotherapy. A rise in thyroid stimulating hormone concentrations is the most sensitive indicator of thyroid dysfunction. Children with raised thyroid stimulating hormone concentrations should be treated with thyroxine.

Endocrine complications of radiotherapy and chemotherapy given to children with brain tumours separated from the hypothalamo-pituitary axis have been documented. ${ }^{1}$ Growth hormone insufficiency is the commonest disorder, ${ }^{2}$ followed by primary thyroid and gonadal dysfunction, and then secondary thyroid and gonadal dysfunction. ${ }^{3}{ }^{4}$ Irradiation is the major aetiological factor, but chemotherapy has been found to cause primary gonadal damage. . $^{5-7}$ There is only limited information from small studies about thyroid function and we report our observations on the prevalence, aetiology, and management of thyroid dysfunction in a large series of survivors.

\section{Patients and methods}

The thyroid function of 119 children in clinical remission after treatment of a brain tumour not involving the hypothalamo-pituitary region was studied. The tumour diagnoses were medulloblastoma $(n=52)$, astrocytoma $(n=29)$, ependymoma $(n=15)$, pinealoblastoma $(n=9)$, glioma $(n=8)$, optic nerve glioma $(n=5)$, and meningioma $(n=1)$. Cranial irradiation in a median (range) estimated hypothalamic dose of $47 \mathrm{~Gy}(10-55)$ in 34 fractions $(30-40)$ was given to all patients and 76 had also received spinal irradiation in a median spinal dose of 31 Gy $(30-33)$ in 25 fractions (20-30) combined in 29 cases with chemotherapy. Four children received cranial irradiation and chemotherapy. The cytotoxic agents were lomustine, vincristine, and methotrexate alone or in varying combinations, usually following the schedules of the International Society of Paediatric Oncology. ${ }^{8}$ The median total doses given were lomustine $550 \mathrm{mg} / \mathrm{m}^{2}(320-1333)$, vincristine $36 \mathrm{mg} / \mathrm{m}^{2}(5-51)$, and methotrexate $1.5 \mathrm{~g} / \mathrm{m}^{2}$ $(0 \cdot 1-4 \cdot 5)$. The median age at the start of radiotherapy as 6.7 years $(1.5-15)$ and median follow up after radiotherapy 8.5 years (1-27).

Serum total thyroxine and thyroid stimulating hormone (by immunoradiometric assay) concentrations were measured in all children at variable intervals after treatment (normal serum thyroid stimulating hormone concentration $<4.8 \mathrm{mU} / \mathrm{l}$, normal total serum thyroxine $60-140 \mathrm{nmol} / \mathrm{l})$. Thyroid stimulating hormone concentrations were also measured by the Delfia method on the same samples in 38 patients for comparison and confirmation (normal thyroid stimulating hormone (Delfia) $<3.8$ $\mathrm{mU} / \mathrm{l}){ }^{9}$ Thyroid stimulating hormone responses to intravenous thyrotrophin releasing hormone $200 \mu \mathrm{g}$ were documented in children undergoing investigation of the hypothalamo-pituitary axis because of poor growth. Thyroid autoantibodies were measured.

Primary thyroid dysfunction was defined as a raised basal serum concentration of thyroid stimu- 
lating hormone supported, if available, by an exaggerated response to thyrotrophin releasing hormone. Secondary hypothyroidism was diagnosed from a low serum thyroxine with low serum thyroid stimulating hormone concentration. Statistical analyses were performed using the Mann-Whitney and $\chi^{2}$ tests.

\section{Results}

A total of 31 of 76 children $(41 \%)$ treated with spinal irradiation had raised basal and peak serum thyroid stimulating hormone concentrations and six of these had low serum thyroxine concentrations (figure). The median basal thyroid stimulating hormone concentration in the affected group was $7 \cdot 8 \mathrm{mU} / \mathrm{l}(5 \cdot 0-39)$, the median peak thyroid stimulating hormone concentration after thyrotrophin releasing hormone was $37 \mathrm{mU} / \mathrm{l}(23-85)$, and the median serum thyroxine concentration was $76 \mathrm{nmol} / \mathrm{l}(10-118)$. Eleven of these children had received only radiotherapy; this was combined with chemotherapy in 20 . As the table shows, there was a

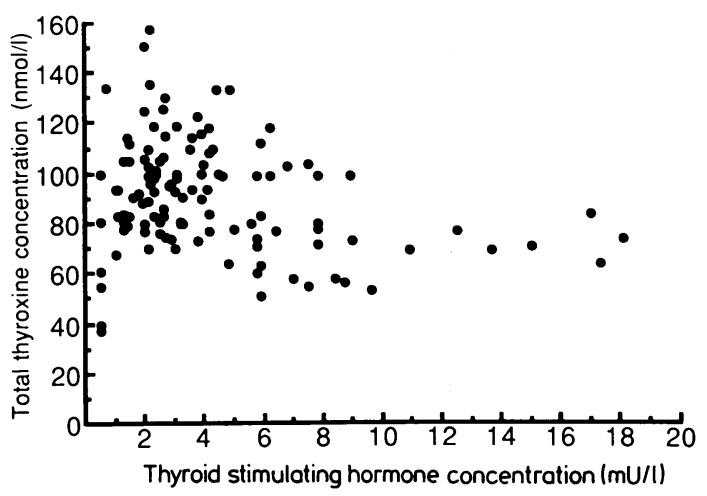

Figure Serum thyroxine and thyroid stimulating hormone concentrations in 119 patients after treatment of brain tumours.

Table Treatment details of patients and primary thyroid dysfunction $(n=119)$

\begin{tabular}{lll}
\hline & \multicolumn{2}{l}{$\begin{array}{l}\text { No of patients with thyroid } \\
\text { dysfunction (total irradiated) }\end{array}$} \\
\cline { 2 - 3 } & $\begin{array}{l}\text { Without } \\
\text { chemotherapy }\end{array}$ & $\begin{array}{l}\text { With } \\
\text { chemotherapy }\end{array}$ \\
\hline $\begin{array}{l}\text { Cranial irradiation } \\
(\mathrm{n}=43)\end{array}$ & $0(39)$ & $2(4)$ \\
$\begin{array}{c}\text { Craniospinal irradiation } \\
(\mathrm{n}=76)\end{array}$ & $11(47)$ & $20(29)$ \\
\hline
\end{tabular}

significant relation between primary thyroid dysfunction and spinal irradiation $(\mathrm{p}<0.01)$, which was expected, but the addition of chemotherapy to spinal irradiation resulted in a significantly increased incidence of thyroid dysfunction compared with that after spinal irradiation alone $(\mathrm{p}<0.001)$.

The cytotoxic agents given to the affected group were lomustine plus vincristine in 19 children and vincristine alone in the other child. There were no significant differences in the doses or timing of cytotoxics, nor in age at treatment between affected and unaffected children. Raised and normal basal serum thyroid stimulating hormone concentrations were confirmed by the alternative Delfia method in the samples tested. No thyroid autoantibodies were detected in affected children.

Two of the four children treated with chemotherapy without spinal irradiation had raised serum thyroid stimulating hormone and low serum thyroxine concentrations (thyroid stimulating hormone $5 \cdot 8 / 8 \cdot 7 \mathrm{mU} / \mathrm{l}$, thyroxine $60 / 56 \mathrm{nmol} / \mathrm{l}$ ). Both had received lomustine alone (figure), but not all children treated with lomustine were affected. No child had abnormal thyroid function after cranial irradiation alone.

Four children had secondary hypothyroidism with a median serum thyroxine of $50 \mathrm{nmol} / \mathrm{l}(37-55)$, median thyroid stimulating hormone $<1 \mathrm{mU} / \mathrm{l}$.

\section{Discussion}

This is the largest study of thyroid function after treatment of brain tumours separated from the hypothalamo-pituitary area. The prevalence of primary thyroid dysfunction was $28 \%$ compared with $3 \%$ for secondary dysfunction. This reflects the expected association between spinal irradiation and primary thyroid dysfunction in this dose range and fractionation. ${ }^{4} 5^{10-12}$ Unexpectedly, we found a significantly higher prevalence of primary thyroid dysfunction after treatment with a combination of chemotherapy and spinal irradiation than after spinal irradiation alone. This effect of chemotherapy has not been reported previously in children. Although the numbers were small, two children treated with cranial irradiation and chemotherapy were affected, which suggested that the toxic effects of chemotherapy may have been independent of those of radiotherapy.

Thyroid damage after treatment of brain tumours and lymphomas in childhood has previously been related to the local irradiation alone even though some of the affected children had also received chemotherapy. The numbers studied were too small to draw other conclusions. ${ }^{511-13}$ Bajorunas et al, for example, described raised serum thyroid stimu- 
lating hormone concentrations in three of 12 children with head and neck tumours treated with chemotherapy and tumour irradiation, but only two of the three had received thyroid irradiation and the chemotherapy given to the third included carmustine and vincristine. ${ }^{14} \mathrm{~A}$ relation between chemotherapy and subsequent primary thyroid dysfunction had been described earlier in 24 of 54 adults treated with chemotherapy alone for advanced Hodgkin's disease. ${ }^{15}$ The cytotoxics were mustine, vincristine/ vinblastine, procarbazine, and prednisolone in combination. In our study the combination of vincristine and lomustine with spinal irradiation obscured whether one or both cytotoxics was responsible for thyroid damage but there was some evidence for lomustine.

Most affected children in this series were biochemically euthyroid, as others have reported, ${ }^{512}$ and an appreciable rise of serum thyroid stimulating hormone concentration was not often seen. If thyroid function had been monitored by measuring thyroxine concentrations alone, most of those affected would have been missed. The management of such children is unclear, ${ }^{1}$ but patients with so called compensated thyroid dysfunction have been shown to have alterations in the cardiac systolic time interval that can be improved by thyroxine replacement. ${ }^{16}$ There is also some evidence that a persistently raised serum thyroid stimulating hormone concentration increases the risk of thyroid cancer after thyroid irradiation. ${ }^{17} 18$ It is not known whether correction of the thyroid stimulating hormone is protective. Our policy, and that of others, ${ }^{15}$ is to monitor serum thyroid stimulating hormone concentrations annually after spinal irradiation or chemotherapy and to treat with thyroxine those in whom the thyroid stimulating hormone is raised.

The interval after treatment to the peak incidence of thyroid dysfunction is not known. ${ }^{1}$ Ours was not a prospective study, but most abnormalities (24 of 33) were detected within four years of completing radiotherapy and three years of completing chemotherapy.

It has been suggested that post irradiation thyroid damage might be an autoimmune phenomenon. Tamura et al found an increased frequency of thyroid antibodies after neck irradiation in patients with lymphoma, ${ }^{19}$ but we did not confirm this finding and the mechanism of the thyroid disturbance requires further study.

This study indicates a requirement to assess thyroid function in children who have received chemotherapy. It reinforces the need for lifelong surveillance of the endocrine function of patients treated with chemotherapy or radiotherapy in childhood.
We are grateful to Drs AC Whitton and $J$ Britton and Professor RP Ekins for their help and to Drs N Godlee, J Tobias, and the late Professor HJG Bloom for access to their patient records. The study was supported by the Cancer Research Campaign.

\section{References}

${ }^{1}$ Shalet SM. Disorders of the endocrine system due to radiation and cytotoxic chemotherapy. Clin Endocrinol 1983;18:637-59.

2 Shalet SM, Beardwell CG, Pearson D, Morris Jones PH. The effect of varying doses of cerebral irradiation on growth hormone production in childhood. Clin Endocrinol 1976;5: 287-90.

${ }^{3}$ Livesey EA, Brook CGD, Whitton AC, et al. Endocrine disorders following treatment of childhood brain tumours. Int $J$ Radiat Oncol Biol Phys (in press)

${ }^{4}$ Shalet SM, Beardwell CG, MacFarlane IA, Morris Jones PH, Pearson D. Endocrine morbidity in adults treated with cerebral irradiation for brain tumours during childhood. Acta Endocrinol 1977;84:673-80.

5 Brown IH, Lee TJ, Eden OB, Bullimore JA, Savage DCL. Growth and endocrine function after treatment for medulloblastoma. Arch Dis Chld 1983;58:722-7.

6 Ahmed SR, Shalet SM, Campbell RHA, Deakin DP. Primary gonadal damage following treatment of brain tumours in childhood. J Pediatr 1983;103:562-5.

7 Livesey EA, Brook CGD. Gonadal dysfunction after treatment of intracranial tumours. Arch Dis Child 1988;63:495-500.

8 Bloom HJG, Thornton Jones H. Adjuvant chemotherapy for medulloblastoma: the multicentre controlled trial of the International Society of Paediatric Oncology (SIOP). Proceedings of the 13th International Congress of Chemotherapy. Vienna, 1983.

9 Lövgren T, Hemmilä I, Pettersson K, Halonen P. Time-resolved fluorometry in immunoassays. In: Collins WP, ed. Alternative immunoassays. Chichester: Wiley, 1985:203-17.

10 Broadbent VA, Barnes ND, Wheeler TK. Medulloblastoma in childhood: long term results of treatment. Cancer 1981;48: 26-30.

1 Duffner PK, Cohen ME, Anderson SW, et al. Long-term effects of treatment on endocrine function in children with brain tumors. Ann Neurol 1983;14:528-32.

12 Oberfield SE, Allan JC, Pollack J, New MI, Levine LS. Long term endocrine sequelae after treatment of medulloblastoma: a prospective study of growth and thyroid function. $J$ Pediatr 1986;108:219-23.

13 Shalet SM, Rosenstock JG, Beardwell CG, Pearson D, Morris Jones PH. Thyroid dysfunction following external irradiation for Hodgkin's disease in childhood. Clin Radiol 1977;28:511-5

14 Bajorunas DR, Ghavimi F, Jereb B, Sonerberg M. Endocrine sequelae of antineoplastic therapy in childhood head and neck malignancies. J Clin Endocrinol Metab 1980;50:329-35.

15 Sutcliffe SB, Chapman R, Wrigley PFM. Cyclical combination chemotherapy and thyroid function in patients with advanced Hodgkins disease. Med Pediatr Oncol 1981;9:439-48.

16 Ridway EC, Cooper DS, Walker H, Rodbard D, Maloof F. Peripheral responses to thyroid hormone before and after l-thyroxine therapy in patients with subclinical hypothyroidism. $J$ Clin Endocrinol Metab 1981;53:1238-42.

${ }^{17}$ Doniach I. Effects, including carcinogenesis, of ${ }^{131} \mathrm{I}$ and X-rays on the thyroid of experimental animals. Health Phys 1963;9: 1357-62.

${ }^{18}$ Lindsay S, Sheline GE, Potter GD, Chaikoff IL. Induction of neoplasms in the thyroid gland of the rat by $\mathrm{X}$-irradiation of the gland. Cancer Res 1961;21:9-16.

19 Tamura K, Shimaoka K, Friedman M. Thyroid abnormalities associated with treatment of malignant lymphoma. Cancer 1981;47:2704-11.

Correspondence to Dr CGD Brook, Endocrine Unit, Middlesex Hospital, London W1N 8AA.

Accepted 21 October 1988 